\title{
From Student-Teachers to Teachers of Students: Beginning Teachers' Journeys from Pre-Service to the Classroom
}

\author{
Irina S. Okhremtchouk ${ }^{1}$, Rosa M. Jiménez², Rebecca Rosa ${ }^{3}$, Susan G. Porter ${ }^{4}$, Navnit Bhandal5, \\ Molly Cramer6, Gregory Lang7, Kevin Magill', Robert Mathrole ${ }^{9}$, Kate Poulin ${ }^{10}$ \\ ${ }^{1}$ The Mary Lou Fulton Teachers College, Division of Teacher Preparation at Arizona State University, Tempe, USA \\ ${ }^{2}$ The International and Multicultural Education Department at University of San Francisco, San Francisco, USA \\ ${ }^{3}$ The Social Science Credential Program in the School of Education at University of California at Davis, Davis, USA \\ ${ }^{4}$ The School of Education at the University of Redlands, Redlands, USA \\ ${ }^{5}$ McGeorge School of Law, Sacramento, USA \\ ${ }^{6}$ El Rodeo Elementary School, Beverly Hills, USA \\ ${ }^{7}$ International School, Tainan, Chinese Taipei \\ ${ }^{8}$ Department of Curriculum \& Instruction, Social Studies, The University of Texas, Austin, USA \\ ${ }^{9}$ Social Studies Department, Heritage High School, Brentwood, USA \\ ${ }^{10}$ Russell High School, Great Falls, USA \\ Email: Irina.O@asu.edu
}

Received 10 February 2015; accepted 8 March 2015; published 11 March 2015

Copyright (C) 2015 by authors and Scientific Research Publishing Inc.

This work is licensed under the Creative Commons Attribution International License (CC BY). http://creativecommons.org/licenses/by/4.0/

(c) (i) Open Access

\begin{abstract}
Given the complexities associated with the retention of beginning teachers nationwide, this article serves as a small window to the professional realities and challenges new to the profession teachers face. In this collaborative inquiry, we attempt to uncover and examine key issues pertaining to the pre-service and induction experiences of beginning teachers. We, teacher educators, utilized an inquiry discourse approach to disseminate findings through a collective voice in which we examined issues beginning teachers encounter and support mechanisms needed with the beginning teachers as compared to about them. This article concludes with a list of recommendations for the beginning teachers, school administrators, and teacher preparation programs.
\end{abstract}

\section{Keywords}

Beginning and New-to-the-Profession Teachers, Turnover and Attrition, Teacher Induction, In-service and Pre-service Teachers, Student-Teachers 


\section{Introduction}

"Everyone goes in thinking they are going to teach like a home-run hitter plays ball, just swinging for the fences every time they are up at bat. This is not the case. Learning through massive failure is more like what actually happened..."

\section{-Gregory Lang, First-year Teacher}

Idealistic and eager to change the world and their students' lives, from the very first day they set foot into their own classrooms, beginning teachers face a $10 \%$ chance of not returning to the profession the following academic year. That number continues to climb during the first five years of induction (Kaiser, 2011). The relative odds of beginning teachers leaving the profession are $184 \%$ higher than for middle-aged teachers, and almost half of beginning teachers leave the profession altogether after the first five years of teaching (Ingersoll, 2001).

The problem of teacher turnover and attrition is crippling to the educational system as well as costly. For the purposes of this article we define teacher turnover as a change in a teacher's assignment from one school year to the next (Boe, Cook, \& Sunderland, 2008). Turnover in teaching profession comes in many shapes and forms, one of which is teacher attrition where, often new-to-the-profession, teachers leave the teaching profession altogether. Thus, teacher attrition is the most devastating one of all turnover types, others being teacher migration and teacher transfer (both in term of classroom/subject matter reassignment and institutional reassignment) (e.g., Kozleski et al., 2000).

National Commission on Teaching and America's Future (NCTAF) estimated that the national cost of public school teacher turnover could be well over $\$ 7.3$ billion a year (NCTAF, 2007). California, the state our study is situated in, employs and prepares $10 \%$ of all teachers in the nation (U.S. Department of Education, 2009)_ where the costs associated with teacher attrition topped \$200 million in 2003 (Alliance for Excellence in Education [AEE], 2005).

A great effort is exercised to ensure a solid education for California pre-service teachers including exit exams via various Teacher Performance Assessments (TPAs) (Okhremtchouk, Newell, \& Rosa, 2013) and mechanisms to secure ongoing growth into the profession during the first two years of induction, i.e., Beginning Teacher Support and Assessment (BTSA). However, the early as well as overall attrition rates amongst California teachers are similar to the national average. Thirteen percent of California beginning teachers leave the profession after the first two years and 22\% are not returning to the profession after their fourth year in the classroom (Reed, Rueben, \& Barbour, 2006). Teacher attrition is a daunting problem for all—be it the students, teachers, or educational system as a whole.

\section{Background: About Our Work and Inquiry Discourse}

Given the complexities associated with the retention of beginning teachers and our desires to shed light on this ongoing concern, we (teacher educators) decided to go to the source-our former students. In this collaborative inquiry project, we attempt to uncover and examine key issues pertaining to pre-service and induction periods. Our inquiry discourse approach is an innovative way to disseminate findings through a collective voice, since methodologically we examine beginning teachers' issues and support mechanisms with teachers as compared to about teachers.

In our journey we attempt to uncover the mechanisms of support that play a critical role in assisting beginning teachers in both (a) pre-service preparation and (b) beginning teaching stages. Nineteen beginning teachers participated in our inquiry discourse project. These teachers received their certification from three types of California institutions (i.e., University of California, California State Universities, and private institutions). The participants have taught between one and three years, and all but one are first career teachers. In our inquiry, we focused on beginning teachers' perceptions of the tools needed to support them in their teacher education programs and places of employment.

We analyzed data using an open-coding method followed by analytic categories, which focused on teachers' perceptions about the most valuable experiences in their teacher preparation programs, what they wished they knew before entering the profession, and what suggestions they would provide for better supporting beginning teachers (both in teacher education programs and at their places of employment). We recalibrated and crossvalidated our initial coding, analysis, and findings with each other in order to promote researcher reflection and test initial assertions (Erickson, 1986; Maxwell, 1996). Then we asked the beginning teacher participants to re- 
view the results of the study and offer suggestions.

\section{Understanding Support Needs for New-to-the-Profession Teachers}

\subsection{From Student-Teachers...}

To start this discussion, we asked beginning teachers to reflect back on their teacher preparation experiences and share which elements were most useful. The collective results have shown that the practical experience during the student teaching phase of the teacher preparation year and content area methods courses were by far the most critical components of the pre-service period.

“...the direct practice of being in the classroom everyday was some of the most valuable experience that I received during my credential program. It provided a place to put into practice the tools given by the program."

"...the best way to become more familiar and better versed in anything is by putting yourself out there, doing the real thing and learning as much as you can from any mistakes you make.”

The feedback received as part of the in-class observations was ranked the second most important component during the pre-service period. Lesson development and preparation, as well as peer resource sharing and support, came in third.

“...the classroom observations by our teacher supervisor was the most important way to reflect on what was working and what needed improvement in our student teaching. After preparing a detailed lesson plan, executing the lesson, our teacher supervisor met individually with us and dissected the lesson... As nerve-racking as observations were, these experiences prepared me for my future career."

"NOTHING can replace hands-on experience and having multiple sets of critical eyes on your lessons/presentations."

"The group discussions were once a week, our cohort would sit in a circle and just begin sharing our student teaching experiences, good and bad, and support one another in a variety of ways. We laughed together, cried together, but most importantly, we realized we were all beginning our teaching careers together.”

As evidence show, it is apparent that genuine dialogue within close-knit relationships - that of teacher-supervisors and peers-provided a meaningful and hands-on apprenticeship into the daily realities of the profession. This socialization into the profession contributed to the learning processes of the pre-service teachers' experiences in an authentic way.

\subsection{To Teachers of Students...}

Along the same lines, the beginning teachers were asked to reflect and comment on what they wished they had known before they began their teaching careers. The number one challenge expressed by the teachers was a lack of awareness about how challenging classroom behavior and management issues would be.

"I went in hoping that something like what happened in Lean On Me was going to happen, but that bubble was burst on the first day. Students can't be forced to do anything, so they have to either be sold on the activity or action or whatever, or there has to be some kind of bargaining (of the non-material variety). Being a failed salesman, that knowledge would have been useful.”

The reference to the movie Lean on Me of a committed, yet hard-lined principal, Joe Clark, who inspires hope and transformation of inner-city youth, reveals an idealized version of what this teacher hoped to experience. While this reference indeed connotes a dedication for working with inner-city youth, the teacher's struggles to engage students seems to result in frustration and leads to a misperception of teaching as a sales job.

Another realization that was not clear during the pre-service period was the extra time outside of work hours required in the teaching profession.

"When I first began teaching I would spend hours outside of work working. As a result, I was stressed out..."

"I wish I would have known truly how much work this job would be."

The red tape bureaucracy and lack of autonomy came-in third.

"Knowing more about what is required of teachers, in regards to basic red-tape type knowledge and other requirements on one's time.”

"I wish I had known what a burden BTSA was going to be."

The other areas mentioned were the type of school one selects for employment does matter, the significance of finding one's own style of teaching, pressure from high-stakes testing, a need for a personal system of organization, job search issues and low morale associated with layoffs, lack of basic resources at the school site level, 
and a need to detach from constant work issues. The following excerpt expresses the realities beginning teachers face in today's California schools:

"I wish I had received some counsel on how to deal with a lay-off and the steps I should take after receiving a pink slip. While I knew there was a possibility that I would receive a pink slip and that it wouldn't be rescinded, it still came as a shock to me... despite trying to keep my head high, the layoff dramatically affected my attitude, work ethic and morale during the end of the school year. I felt that I had worked my tail off and I was being kicked to the curb as a reward. I wasn't sure how to begin my job search or if I should expect to be rehired..."

The current national economic downturn, the state of California's budgetary crisis at-large, and deep-cuts to public education call for increased preparation of teachers, especially new ones, to manage the logistical and emotional toll of being pink-slipped or laid off.

\subsection{Journeys into the Classroom}

In their suggestions pertaining to support needed at the school sites, beginning teachers overwhelmingly expressed the need for a "veteran teacher buddy system".

"I think the school could have supported me by pairing me up with teachers leading similar classes. That way, I would have had an opportunity to discuss/brainstorm/receive feedback on my methods of instruction for the courses."

“...it is immensely useful to have a veteran teacher that can assist a new teacher with lesson plans, power points, and activities. Constructing a year's worth of lesson for one class, much less two or three different classes, is far too much for one teacher to do by themselves. Sadly, that seems to be what most teachers have to go through, and it resembles a trial by fire-sort of tribal initiation.”

The teachers in this study called for a greater collaboration—one that went beyond checking in once in a while with a fellow teacher to one of meaningfully being apprenticed into all functions of the profession.

A need for practical tools in both teaching materials and how to navigate the system came in second.

"I have not received any copies of the school rules, teacher phone codes, etc. My school essentially threw me in a room without any guidance concerning their procedures or expectations."

"Grants, scholarships...it takes a lot to start a classroom from scratch."

"I believe new teachers should be provided with a packet to help them adjust to their first year of teaching. The packet should include a copy of the pacing guide, state standards, a calendar of school events, and a list of contacts."

Teachers equated being thrust into some of their first teaching experiences similar to a "sink-or-swim" modelthat is, without many of the basic necessities to stock their classrooms nor guidance about classroom and schoolwide policies.

Assistance with classroom discipline and a lack of support from management were third.

“...the administration needs to be more supportive of new teachers... [and] be aware of what goes on in the classroom. They also need to make more of an effort to support new teachers in matters related to grades and discipline."

The other feedback suggested that department meetings to specifically address beginning teacher needs would be helpful, BTSA program is ineffective, time consuming, and a repeat, there is a need for on-going collaboration time with colleagues, and issues associated with too many different classes taught.

\section{Lessons Learned and Recommendations for...}

\subsection{Beginning and New-to-the-Profession Teachers}

Beginning teachers are very impressionable, hardworking and determined. Being new to the profession, the biggest priority is to survive the school year. This combined with the expectations from parents, administrators, and students can make teaching very overpowering. There were times when it was hard for the beginning teachers to remember why they entered the teaching profession.

As a result, it is important for new teachers to have a strong support system at work and home. The first suggestion would be to use whatever little time available (e.g., during lunch, before or after school) to build professional and other networks at work and beyond. Beginning teachers need outlets where ideas can be brainstormed and shared, as well as a safe environment to confide in and interact with colleagues.

In addition, beginning teachers must never lose sight of and always have time to reflect on their teaching 
practices. An ongoing reflection on their own teaching practice would help them grow as professionals. Of course, it is easier said than done, since beginning teachers are overwhelmed with an array of tasks, but being cognizant of an ongoing development of teaching skills will ensure "ownership" of these skills as compared to simply "doing your job". In short, reflecting on one's own teaching practices will help beginning teachers not only to survive during the induction years, but assist with the ownership of the professional skills needed to be successful for years to come.

Lastly, as hard as it may be, it is important for the beginning teachers not to take their work home. Constantly taking work home will only contribute to an ongoing stress and limit the time needed to recuperate from the demands placed on them. The teaching profession is very time consuming, especially during the first years of teaching. That said, reflecting back, beginning teachers wished that they had kept the work-tasks at work. Staying an hour or two after school or arriving at work early to complete grading or another task would be a much better strategy.

\subsection{School Administrators}

It is critical for school administrators to be flexible and realize that each teacher will face unique challenges. Communicate with beginning teachers to make sure that they are being supported in a way that is helpful to them. One suggestion would be to organize beginning teacher discussion groups with veteran teachers at the school site in order to bounce ideas off of one another, share effective teaching strategies, and problem-solve. Such discussions would organically generate a "veteran-teacher buddy system", which is very much needed and desired by the beginning teachers.

In interacting with the beginning teachers, school administrators need to avoid patronizing them. Administrators at all levels need to encourage and socialize beginning teachers into the profession. Constructive criticism and positive feedback are always useful and very much welcomed. District-wide new teacher training facilitated by veteran teachers and lead by district and school administrators would help socialize beginning teachers into the profession in a collaborative way. Such meetings should focus on the district's vision, the school sites' goals and the community. In other words, conversations about how the leadership sees beginning teachers fitting in are essential.

School administrators should keep in mind that beginning teachers have a heavy workload as they learn to balance grading with planning and so forth. It is critical to make an effort to limit the number of additional duties administrators assign to beginning teachers as well as the number of class preparations. For example, school administrators should set a limit of two different classes that beginning teachers teach a six-period day. Along these lines, revamp or do away with the BTSA program, which is a repeat of what is done during the credential year and takes up time that could be better spent planning lessons, and collaborating with colleagues.

To ensure that beginning teachers are successful, school administrators need to provide them with important information, such as a school phone directory, pacing guides, school rules, information on technology (e.g., email, grading system, etc.), school discipline policies (e.g., teacher's role, administrator's role, etc.), up front. Also, administrators need to be clear about discipline policies and support new teachers when they enforce them.

Finally, administrators should provide beginning teachers with a small stipend (start-up funds) to buy necessary supplies for their classrooms. Classroom materials do matter and make a difference in educational experiences of the students. Beginning teachers should not be the ones buying these materials to ensure that their students are successful. In other words, administrators need to learn a lesson from their teachers: in order to achieve success, one must have the tools needed to facilitate it.

\subsection{Teacher Education Programs}

In reflecting on the complex process of educating the educator, a few key elements stand out as core necessities for producing a competent practitioner. First, establishment of basic principles of practice before entering the classroom is crucial. Development of lesson and unit plan structure as well as the basic teaching principles that produce effective versions of these items should precede full practice. However, fundamental knowledge of principles of effective lesson development certainly does not ensure best practice within the classroom.

This issue directly relates to the second key element of teacher preparation-practice. Once pre-service teachers have established a background in fundamental principles of lesson development and delivery, practice is the only way to actually produce effective classroom practitioners. The current system focuses on providing 
teachers an integrative system that tiers progression from classroom aid to acting teacher. In that, pre-service teachers are given the chance to develop skills and experience failures that support the learning process. Much like residency for medical doctors, teacher education should function on an apprenticeship model.

Such a model requires that apprentices have highly skilled resident teachers (those that are primarily in charge of skill development during student teaching stages). The current vetting process for resident teacher selecting practices is flawed. Resident teachers often do not provide adequate support to apprentices (student teachers) or demonstrate levels of mastery that would be adequate for modeling purposes. The surveys amongst colleagues have revealed that significant numbers of resident teachers provided little to no lesson plan support, classroom management techniques, or valuable observational feedback. Instead, apprentices are viewed as substitutes for resident teachers and are expected to "sink or swim" with intervention only occurring when serious problems have already arisen.

Ultimate recommendations for improvement in teacher education programs relate to improving the studentteaching system and experience for pre-service teachers. While the number of resident teachers needed to fill the need will likely produce logistical problems, providing masters in the field for apprentice teachers to collaborate with is of the utmost importance. University advisors should be required to extensively observe potential resident teachers and remove those who are not acting in the interest of pre-service teacher development. Such improvements would maximize the benefits of the apprenticeship model and significantly improve the level of proficiency as well as the professional knowledge needed in beginning teachers.

\section{Conclusion}

This article serves as a small window to the professional realities and challenges beginning teachers encounter. In order to resolve these challenges, the issues associated with teacher preparation and induction must be addressed on multiple grassroots levels. The beginning teachers desperately desire a mentor at their school sites with whom they can collaborate and who would serve as their advocate. Such mentorship should not be confused with or substituted by an already mandated statewide BTSA program, which was described as ineffective and a repeat by the beginning teachers. This mentorship should be organic in nature and serve as a support mechanism for beginning teachers as compared to class observations and dubious paperwork associated with BTSA.

Moreover, support needs pertaining to tools needed to be successful in one's own classroom and assistance with behavior management should not be overlooked. The sink-or-swim initiation into the profession will not ensure beginning teacher retention, but rather the opposite. Simply put, solutions that matter are much more grassroots than statewide mandates. The sources of support must situate themselves within, be it at the place of employment or pre-service student-teaching placements.

In all, even with all the obstacles to overcome, one of the first recommendations beginning teachers made to their colleagues is to be cognizant of an ongoing development of teaching skills to assist with the ownership of the professional skills needed to be successful for years to come. That said, all who are responsible for supporting these new professionals and those who prepare them would benefit from the advice their subordinates and former student-teachers give themselves—never lose sight of what is important and who makes the difference.

\section{References}

Alliance for Excellent Education [AEE] (2005). Teacher Attrition: A Costly Loss to the Nation and to the States. Issue Brief, Washington, DC: Alliance for Excellent Education.

Boe, E. E., Cook, L. H., \& Sunderland, R. J. (2008). Teacher Turnover: Examining Exit Attrition, Teaching Area Transfer, and School Migration. Exceptional Children, 75, 7-31.

Erickson, F. (1986). Qualitative Methods in Research on Teaching. In M. Wittrockk (Ed.), Handbook of Research on Teaching (3rd ed., pp. 119-161). New York: MacMillan.

Ingersoll, R. (2001). Teacher Turnover, Teacher Shortages, and the Organization of Schools. Seattle, WA: Center for the Study of Teaching and Policy, University of Washington.

Kaiser, A. (2011). Beginning Teacher Attrition and Mobility: Results from the First through Third Waves of the 2007-08 Beginning Teacher Longitudinal Study (NCES 2011-318). Washington, DC: National Center for Education Statistics. U.S. Department of Education. http://nces.ed.gov/pubsearch

Kozleski, E., Mainzer, R. W., Deshler, D., Coleman, M. R., \& Rodriguez-Walling, M. (2000). Bright Futures for Exceptional Learners: An Agenda to Achieve Quality Conditions for Teaching and Learning. Arlington, VA: Council for Exceptional Children. 
Maxwell, J. A. (1996). Qualitative Research Design: An Interactive Approach. Thousand Oaks, CA: Sage Publications.

National Commission on Teaching and America's Future [NCTAF] (2007). Policy Brief: The High Cost of Teacher Turnover. Washington, DC.

Okhremtchouk, I., Newell, P., \& Rosa, R. (2013). Assessing Pre-Service Teachers Prior to Certification: Perspectives on the Performance Assessment for California Teachers (PACT). Education Policy Analysis Archives, 21, 31 p. http://epaa.asu.edu/ojs/article/viewFile/1263/1122

Reed, D., Rueben, K. S., \& Barbour, E. (2006). Retention of New Teachers in California. San Francisco, CA: Public Policy Institute of California.

U.S. Department of Education, Office of Postsecondary Education (2009). The Secretary's Sixth Annual Report on Teacher Quality: A Highly Qualified Teacher in Every Classroom. Washington, DC. 